\title{
Library Seminars: Keeping Faculty Informed
}

Reference librarians at Michigan State University had discussed for some time the need for a systematic program to inform faculty and graduate students of new reference tools and library services augmented or altered by automation. In the summer of 1979, after one reference librarian attended an ALA preconference on library instruction for graduate students and faculty, planning began for a fall term faculty seminars pilot project. Cooperatively developed by reference librarians, this series reviewed reference sources thought to be undiscovered or under-used by researchers and teaching faculty. Most of the seminars were organized into broad subject divisions: social science, humanities, education, music, and government documents; two others presented a library services and resources overview to new faculty and introduced computer-assisted literature searching. Attendance was good and registrant evaluations were positive; the Library Sem. inars Program was launched.

The following summer a committee was formed to plan and coordinate a long range program. During the 1980/81 academic year a more diverse and ambitious schedule of seminars was developed. Initially planned for fall and winter terms, the series was later extended into the spring term in order to repeat several seminars for which interest exceeded room capacity during the winter term. The audience grew from the original target group of MSU faculty and graduate students to include area librarians and government researchers who were attracted to particular sessions.

The planning committee solicited, from all library faculty, seminar topics and volunteers to prepare and give seminars; selected a final roster of speakers and topics; set guidelines for preparations and hand-outs; arranged for audio-visual and online equipment and rooms; made coffee; and prepared and disseminated the publicity, A checklist of presentations skills and preparation methods was developed and discussed at a meeting of seminar givers before each series began. Standardized evaluation forms were designed and distributed at each seminar. Follow-up sessions were held at the end of each term incorporating data from the returned evaluation forms with observations from seminar givers and from the committee. At the beginning of the winter series, a consultant from Learning and Evaluation Ser- vices, an MSU program providing, among other services, assistance with teaching methods and materials, conducted a workshop for librarian participants; he also attended several subsequent seminars and prepared written evaluations.

This 1980/81 seminar series was expanded both to include the scientific and business disciplines and to offer more specialized presentations. Some programs surveyed search techniques and use of reference sources in particular fields such as women's studies, bio-medicine, international business, energy, music, English and American literature, and law. Other sessions concentrated on use of specific reference works such as the citation indexes or the Congressional Information Service's indexes. Still others covered organization of, and access to, information within government publications and U.S. census reports. Particularly well-attended were seminars of a more general interest: an introduction to the library developed for new faculty, a program on the library's computerized circulation system with public-access terminals, and sessions covering current copyright legislation, computer-assisted literature searching, and foundation, corporate, and federal grants.

For many of the seminars it was possible to draw on the expertise of MSU librarians; for others, speakers were invited from outside the library. For example, lecturers from the Institute for Scientific Information, the U.S. Census Bureau, and the university administration participated each term. Most of the programs were scheduled to last two hours. The methods of presentation used most often were lectures by either one speaker or a team augmented by audio-visual aids or demonstrations of computer searching. Printed bibliographies and guides to the use of specific reference tools were given to all attendees. Discussion, a vital part of any seminar, was encouraged, and seminar enrollment was limited to maintain an informal atmosphere.

The most effective publicity proved also to be the most expensive and the most timeconsuming. Flyers describing the seminars were mailed to departments for distribution to faculty and graduate students by departmental secretaries and for posting on bulletin boards. A registration form to be returned to the library was enclosed with each flyer. Announcements were placed in the weekly MSU News Bulletin, the 
faculty/staff newsletter; the University Libraries, a quarterly library publication; and a number of departmental newsletters. The MSU News Bulletin proved to be the second most effective publicity method. Copies of the flyer were made available to the MSU branch libraries, and to the Main Library reference desks. Confirmation of registrations was also time-consuming but resulted in much better attendance. Many people attended more than one session and professors encouraged their graduate students to attend particular sessions. In this way, the seminars have begun to publicize themselves.

These seminars have had a variety of benefits, some of them indirect. Unquestionably, the participants learn a great deal and come back the next term if they were drawn to a seminar relevant to their needs. The program as a whole provides very good public relations for the library. Like other instructional programs, this one has increased demands for computerized literature searches and for specialized help in some subject areas. Librarians, of course, learn much about both their resources and their patrons in the process of seminar preparation. Finally, it appears that the seminar program is an effective but unobtrusive way to help regular library users adjust to the machine-age library.

Has it been worth the effort? Opinions of the library staff involved in the planning and presenting of the seminars are definitely positive, although there is an acknowledgment of the large amount of time spent on preparation and on publicity. Those librarians skeptical of the benefits of library instruction for any group remain unconvinced, despite the good will towards the library and librarians this program seems to be generating. That some sort of continuing education in library usage is needed for advanced researchers is beyond doubt; the kind of series reported here may prove to be a useful, flexible means to provide this group with information and training, particularly as technology continues to transform the library.-Linda de Wit, Agnes Haigh, and Julie Hurd.

Editor's Note: Linda de Wit and Agnes Haigh are reference librarians at Michigan State University, East Lansing; Julie Hurd is science librarian at $M S U$.

\section{Library Organization Development at Northeastern University}

\author{
Thomas H. Cahalan, Chair \\ Northeastern University Library \\ Organization Development \\ Study Team
}

A library organization development program is being conducted at Northeastern University, Boston, as a result of a survey of library staff members which indicated a high interest in organizational change. Plans for the program are based on recommendations given in a report of a study of the Management Review and Analysis Program (MRAP), a self-study program designed by the Association of Research Libraries Office of Management Studies and used in more than 20 large academic libraries. ${ }^{1}$ These include giving careful consideration throughout the study to the feasibility of implementing recommendations being developed, having the study team work closely with the Dean of Libraries and Learning Resources, and providing for consultation of $\mathrm{NU}$ administrators, faculty, and students as well as widespread participation of library staff.

The first phase of the program includes selected modules of the Academic Library Development Program (ALDP), a self-study program designed by ARL/OMS for use in medium-sized academic libraries. Because of plans for an architectural competition for the design of a new central library facility, it is focusing on desired organizational changes with implications for the design of the new facility. Funds for this phase, to be completed by March 1982, are being provided by the National Endowment for the Arts Design Arts Program on a matching basis in consideration of funds being spent by NU for the design competition and in accordance with NEADAP policy of fostering excellence in design by promoting design competitions. Jeffrey J. Gardner of ARL/OMS is serving as the organization consultant for this phase, and an internal study team to direct the self-study is chaired by Thomas $\mathrm{H}$. Cahalan, assistant librarian for acquisitions.

The first two units of the study have been concerned with planning for integration of the individual libraries in the new facility and planning for integration of various reference services now segregated because of the design of the present main library building. Reports of both of the task forces involved have been fully accepted for implementation by the library administration.

The method of selection and the composition of the study team provides an interesting model for a library organization development program. In- 